\title{
Modelling of Affinity Separation by Batch and Fixed Bed Adsorption - a Comparative Study
}

\author{
P. Sridhar *
}

\begin{abstract}
Affinity separation can be achieved by batch and fixed bed modes. Mathematical models including film mass transfer, intraparticle diffusion, and reversible reaction are formulated for both fixed bed and batch adsorption processes. Orthogonal collocation method is used to numerically evaluate the performance of batch and fixed bed adsorption. The efficiencies are evaluated in terms of both the solute recovery and adsorbent utilization. The effect of the foilowing parameters is simulated for the comparison purpose: solute concentration, reaction kinetics, ligand content, and particle size. Fixed bed mode is found to be efficient.
\end{abstract}

\section{Introduction}

Affinity separation owes its power as a purification method to specific biological interactions. The underlying concept of affinity separation is simple: a feed is contacted with a solid phase that has a high affinity for the solute of interest. After the solid phase has been saturated it is washed to remove non-specifically adsorbed contaminants. The solute is collected after disrupting the specific interactions. A large number of affinity systems have been developed for a wide variety of separations [1-3].

Affinity separations are generally operated in a fixed bed mode. As the concentration of the solute of interest present in the feed solution is extremely low [4], the fixed bed adsorption requires the passage of a large quantity of liquid through the bed. High flow rates result in poor adsorption efficiency. The mechanically soft properties of the affinity adsorbent may also preclude high flow rates. Under these circumstances, the fixed bed adsorption requires a long operation time. The elution step requires a much shorter time, because only a small quantity of eluent is necessary. The adsorption step requires the longest time among the steps of affinity separation. In order to achieve an effective process, it is necessary to reduce the adsorption time.

In a batch mode, the solute can be adsorbed quickly from a large quantity of dilute solution. For the purification of crude extracts, batch mode may be preferable to avoid column clogging problems. Arnold et al. [5] presented the theory of fixed bed adsorption as is applied to affinity chromatography. This theory provided analytical tools for evaluating and predicting industrial scale affinity column performance, based on data from laboratory-scale experiments. Design equations were included for continuous separations on a rotating annular chromatograph and for batch operation of adsorption and wash steps. The fundamental advantage of fixed bed adsorption over batch adsorption was illustrated. The fixed bed adsorber is capable of reducing the solute concentration in the feed stream to very low levels. The conclusion from their study was that fixed bed adsorption was faster over batch adsorption. Firouztale et al. [6] presented the modelling equations for both the fixed bed and batch adsorption operations. In their study a systematic approach was employed to determine values of key parameters that quantify a given separation by macroporous resins. Yang et al. [7] evaluated the performance of a combined process, i.e., batch adsorption and fixed bed elution. They concluded that batch adsorption requires less time for the operation for dilute solutions than the fixed bed adsorption and the combined process allowed an efficient separation with regard to process time. The solute concentration in the liquid phase and solid phase were related by the Langmuir equilibrium relation. Sridhar et al. [8] had studied the effect of axial dispersion, solute concentration, ligand content, reaction kinetics, particle porosity, particle size, and flow rate on the breakthrough behaviour of a solute in an affinity packed bed.

There has as yet been no theoretical analysis of the relative performances of a given quantity of affinity solid phase used in either a batch or a fixed bed system. The purpose of the present study is to evaluate the suitability of the batch and the fixed bed modes for the adsorption stage.

\section{Model Formulation - Adsorption}

In the adsorption step, solute $\mathrm{P}$ of interest gets adsorbed onto the matrix on which the ligand $\mathrm{L}$ is immobilized. The affinity interaction between the protein and vacant immobilized ligand is assumed be of the form: ${ }^{1)}$

$$
\underset{\text { (protein) }}{\mathrm{P}}+\underset{\text { (ligand) }}{\mathrm{L}} \rightleftharpoons \underset{\text { (complex) }}{\mathrm{PL}}
$$

Monovalent adsorption is considered in the present study. Assuming that the affinity interaction is second order in forward direction and first order in reverse direction, the

\footnotetext{
* P. Sridhar, Research Associate, Department of Chemical Engineering, Indian Institute of Science, Bangalore 560 012, India.
}

1) List of symbols at the end of the paper. 
mass balance equation for solute adsorbed on solid phase can be written as:

$\frac{\partial q_{\mathrm{i}}}{\partial t}=k_{1} C_{\mathrm{i}}\left(Q_{\mathrm{m}}-q_{\mathrm{i}}\right)-k_{2} q_{\mathrm{i}}$

Eq. (1) simplifies to Langmuir's isotherm at equilibrium.

$q_{\mathrm{i}}=\frac{Q_{\mathrm{m}} C_{\mathrm{i}}}{\left(K_{\mathrm{D}}+C_{\mathrm{i}}\right)}$

The following basic assumptions are needed for the general rate models used in this study. It has been assumed that the effective diffusivity is independent of concentration, mass transfer to the surface of the adsorbent is governed by a film model [9] characterized by a mass transfer coefficient $k_{\mathrm{f}}$, and the immobilized ligand is distributed uniformly throughout the interior of the particle. Fig. 1 shows the batch adsorption model. The bulk liquid has a solute concentration $C(t)$. The particles are spherical with radius $R$. The concentration of the solute adsorbed on the porous bead is $q_{\mathrm{i}}(r, t)$ and the solute concentration in the pores is $C_{\mathrm{i}}(r, t)$.

The model developed for the packed bed incorporates the typical features of an affinity column packed with porous particles which is schematically represented in Fig. 2. The

Fluid Film

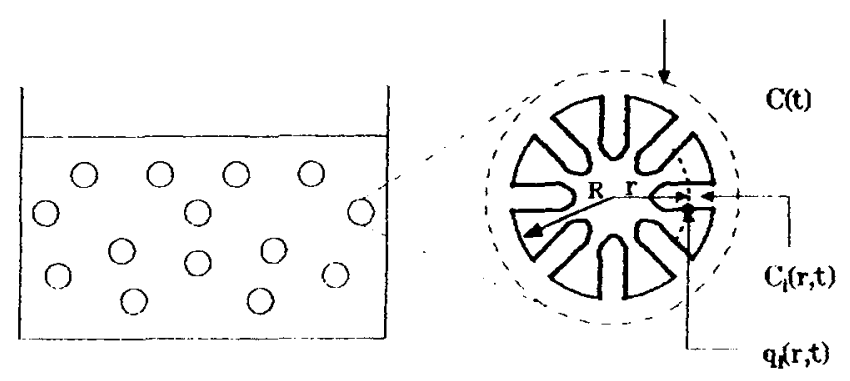

Figure 1. Model of the batch affinity adsorption.

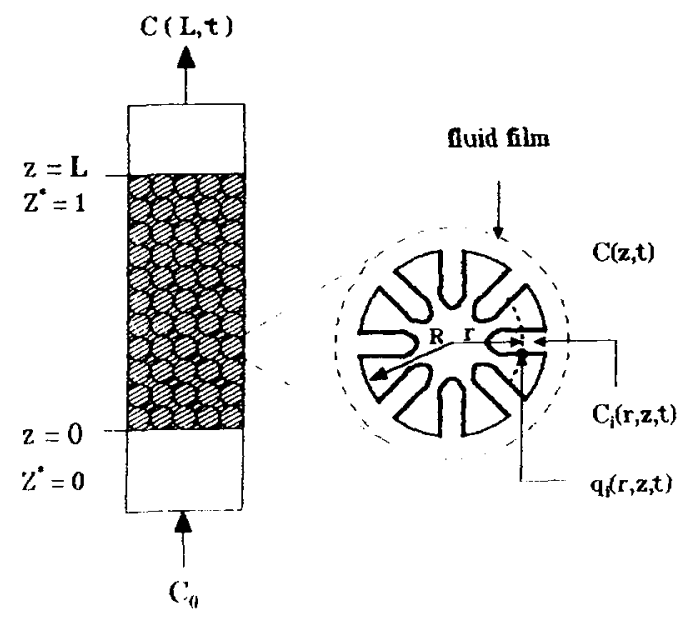

Figure 2. Model of the affinity packed column. model is based on the isothermal sorption of a single solute in dispersed plug flow through a packed column of monodisperse porous particles. The bulk liquid has a solute concentration $C(z, t)$, with an interstitial velocity $u_{\mathrm{i}}$ through a bed of length $L$, and void fraction $\varepsilon$. The particles are spherical with radius $R$. The concentration of the solute adsorbed on the porous bead is $q_{\mathrm{i}}(r, z, t)$ and the solute concentration in the pores is $C_{\mathrm{i}}(r, z, t)$.

The mass balance in the batch adsorber yields the following equation.

$\frac{\mathrm{d} C}{\mathrm{~d} t}=\frac{-3 V_{\mathrm{s}}}{R V_{\mathrm{L}}} k_{\mathrm{f}}\left(C-\left.C_{\mathrm{i}}\right|_{r=R}\right)$

which is subject to the initial condition. At $t=0$ :

$C=C_{0}$

A mass balance over a section of the affinity packed column gives the following continuity relation:

$u_{\mathrm{i}} \frac{\partial C}{\partial Z}+\frac{\partial C}{\partial t}+\frac{3 V_{\mathrm{s}}}{R V_{\mathrm{L}}} k_{\mathrm{f}}\left(C-\left.C_{\mathrm{i}}\right|_{r=R}\right)=E_{\mathrm{z}} \frac{\partial^{2} C}{\partial Z^{2}}$

The various terms in the above equation account for convective transfer of the solute, accumulation in the interstitial spaces, solute uptake in the porous beads, and axial dispersion respectively.

Assuming that there is no protein in the column in the beginning, the initial conditions can be written as follows.

Initial conditions at $Z \geq 0, t=0$ :

$C=0, \quad C_{\mathrm{i}}=0, \quad q_{\mathrm{i}}=0$

In order to include axial dispersion at the inlet of the column, and mixing at the exit of the column, the Danckwerts' boundary conditions [10] are used.

Boundary conditions for the column at $Z=0$ :

$u_{\mathrm{i}} C_{0}=u_{\mathrm{i}} C-E_{\mathrm{z}} \frac{\partial C}{\partial Z}$

At $Z=L$ :

$\frac{\partial C}{\partial Z}=0$

In general, axial dispersion should be considered at the entrance of the column because a steep first-order spatial gradient exists there. When axial dispersion is insignificant, i.e., $E_{\mathrm{z}}$ approaches zero, Eq. (9) reduces to $C=C_{0}$ at the entrance, which is the case of a step input. 
The mass balance in the particle yields:

$D_{\mathrm{i}}\left(\frac{\partial^{2} C_{\mathrm{i}}}{\partial r^{2}}+\frac{2}{r} \frac{\partial C_{\mathrm{i}}}{\partial r}\right)-\frac{\partial C_{\mathrm{i}}}{\partial t}-\frac{\partial q_{\mathrm{i}}}{\partial t}=0$

Boundary conditions for the particle at $r=0$

$$
\frac{\partial C_{\mathrm{i}}}{\partial r}=0
$$

The concentrations $C_{\mathrm{i}}$ and $C$ in the pores of the particle and in the bulk liquid surrounding the particle respectively are coupled by the rate of mass transfer through the fluid film, at $r=R$ :

$k_{\mathrm{f}}\left(C-\left.C_{\mathrm{i}}\right|_{r=R}\right)=\left.D_{\mathrm{i}} \frac{\partial C_{\mathrm{i}}}{\partial r}\right|_{r=R}$

The model equations for the particle are valid for both batch and column models. The above equations are nondimensionalized by the following dimensionless variables:

$Y_{1}=q_{\mathrm{i}} / Q_{\mathrm{m}}, \quad Y_{2}=C_{\mathrm{i}} / C_{0}, \quad Y_{3}=C / C_{0}$

$R^{*}=r / R, \quad Z^{*}=z / L, \quad T=t D_{\mathrm{i}} / R^{2}$.

In the new coordinates, the above Eqs $(1-11)$ get transformed to

$\frac{\partial Y_{1}}{\partial T}=H_{1} Y_{2}\left(1-Y_{1}\right)-H_{2} Y_{1}$

$Y_{1}=\frac{Y_{2}}{\left(H_{3}+Y_{2}\right)}$

$\frac{d Y_{3}}{d T}=-H_{4} \mathrm{Bi}\left(Y_{3}-Y_{2}\right)$

$Y_{3}=0$

$\frac{\partial Y_{3}}{\partial T}=H_{5} \frac{\partial^{2} Y_{3}}{\partial Z^{* 2}}-H_{6} \frac{\partial Y_{3}}{\partial Z^{*}}-H_{4} \mathrm{Bi}\left(Y_{3}-Y_{2}\right)$

$Y_{3}=0, \quad Y_{2}=0, \quad Y_{1}=0$

$1=Y_{3}-\frac{1}{\operatorname{Pe}} \frac{\partial Y_{3}}{\partial Z^{*}}$

$\frac{\partial Y_{3}}{\partial Z^{*}}=0$

$\frac{\partial Y_{2}}{\partial T}=\nabla^{2} Y_{2}-H_{7} \frac{\partial Y_{1}}{\partial T}$

$\frac{\partial Y_{2}}{\partial R^{*}}=0$
Table 1. Dimensionless constants.

\begin{tabular}{|c|c|}
\hline Constant & Definition \\
\hline \multirow[b]{2}{*}{$H_{1}$} & $\underline{k_{1}} R^{2} C_{0}$ \\
\hline & $D_{\mathrm{i}}$ \\
\hline \multirow{2}{*}{$\mathrm{H}_{2}$} & $\underline{k_{2} R^{2}}$ \\
\hline & $D_{\mathrm{i}}$ \\
\hline \multirow{2}{*}{$\mathrm{H}_{3}$} & $\underline{K_{\mathrm{D}}}$ \\
\hline & $C_{0}$ \\
\hline \multirow{2}{*}{$H_{4}$} & $3 V_{\mathrm{s}}$ \\
\hline & $V_{\mathrm{L}}$ \\
\hline \multirow{2}{*}{$H_{5}$} & $\underline{E_{z} R^{2}}$ \\
\hline & $L^{2} D_{\mathrm{i}}$ \\
\hline \multirow{2}{*}{$H_{6}$} & $\underline{u_{\mathrm{i}} R^{2}}$ \\
\hline & $D_{\mathrm{i}} L$ \\
\hline \multirow{2}{*}{$H_{7}$} & $\underline{Q_{\mathrm{m}}}$ \\
\hline & $C_{0}$ \\
\hline \multirow{2}{*}{$\mathrm{Bi}$} & $\underline{k_{\mathrm{f}} R}$ \\
\hline & $D_{\mathrm{i}}$ \\
\hline \multirow{2}{*}{$\mathrm{Pe}$} & $\underline{L u_{\mathrm{i}}}$ \\
\hline & $E_{\mathrm{z}}$ \\
\hline
\end{tabular}

$\left.\frac{\partial Y_{2}}{\partial R^{*}}\right|_{R^{*}=1}=\mathrm{Bi}\left(Y_{3}-\left.Y_{2}\right|_{R^{*}=1}\right)$

where constants $H_{1}$ through $H_{7}, \mathrm{Bi}$, and $\mathrm{Pe}$ are defined in Tab. 1.

\section{Numerical Solution Strategy}

The batch and fixed bed model equations are solved numerically by the orthogonal collocation technique $[11,12]$.

The computer code for the governing mathematical equations is written in FORTRAN. The simulation is done by utilizing NAG routine (D02EAF) on Vax 88 system. This routine integrates a stiff system of second order ordinary differential equations, using a variable order variable step Gear method. Nine collocation points in the column $(0$, $0.02545,0.12923,0.29708,0.5,0.70292,0.87077,0.97455$, $1.0)$ and six collocation points $(0.24929,0.48291,0.68619$, $0.84635,0.95331,1.0$ ) for the particle are used for fixed bed simulation studies. For the batch case, six collocation points $(0.24929,0.48291,0.68619,0.84635,0.95331,1.0)$ for the particle are used. 


\section{Results and Discussion}

For the comparison purpose the effect of solute concentration, ligand loading, reaction kinetics, and particle size has been evaluated in terms of solute recovery and adsorbent utilization efficiencies for both the batch and column modes. For the packed bed case, solute concentration profiles are evaluated with respect to time, i.e., in the form of a breakthrough curve or a frontalgram.

The base case parameter values used in the simulation are listed in Tabs. 2 and 3 and are used throughout unless stated otherwise. For the comparative study, the efficiencies are evaluated at $120 \mathrm{~min}$. At this time, the dimensionless effluent concentration is 0.315 . This is used as a common basis for the evaluation of fixed bed efficiencies for different values of the parameters as shown in Tabs. 4 and 5 . The fixed bed chosen for the present study is of $10 \mathrm{~cm}$ in length and $2 \mathrm{~cm}$ in diameter. The volume of the solid phase used in fixed bed and batch adsorption is same. In $120 \mathrm{~min}$, the fixed bed processes $429.85 \mathrm{~cm}^{3}$ of solution, which is taken as the volume of the liquid phase in the batch adsorber. Axial dispersion coefficient is calculated by using Yamamoto's method [13].

The validity of numerical codes for the orthogonal collocation method are checked before proceeding to the simulation of both batch and fixed bed models. Experimental data of Chase [14] are utilized for the batch model verification.

Table 2. Data for batch model simulation.

\begin{tabular}{llrl}
\hline Symbol & Unit & \multicolumn{2}{c}{ Value } \\
\hline$C_{0}$ & {$\left[\mathrm{~g} \mathrm{~cm}^{-3}\right]$} & 1.7 & $10^{-3}$ \\
$D_{\mathrm{i}}$ & {$\left[\mathrm{cm}^{2} \mathrm{~s}^{-1}\right]$} & 4.5 & $10^{-8}$ \\
$k_{1}$ & {$\left[\mathrm{~cm}^{3} \mathrm{~g}^{-1} \mathrm{~s}^{-1}\right]$} & 5.0 & \\
$k_{2}$ & {$\left[\mathrm{~s}^{-1}\right]$} & 9.5 & $10^{-5}$ \\
$k_{\mathrm{f}}$ & {$\left[\mathrm{cm} \mathrm{s}^{-1}\right]$} & 4.0 & $10^{-4}$ \\
$Q_{\mathrm{m}}$ & {$\left[\mathrm{g} \mathrm{cm}^{-3}\right]$} & 40 & $10^{-3}$ \\
$R$ & {$\left[\mathrm{~cm}^{3}\right.$} & 5 & $10^{-3}$ \\
$V_{\mathrm{S}}$ & {$\left[\mathrm{cm}^{3}\right]$} & 18.85 \\
$V_{\mathrm{L}}$ & {$\left[\mathrm{cm}^{3}\right]$} & 429.85 \\
\hline
\end{tabular}

Table 3. Data for packed bed model simulation.

\begin{tabular}{llll}
\hline Symbol & Unit & \multicolumn{3}{c}{ Value } \\
\hline$C_{0}$ & {$\left[\mathrm{~g} \mathrm{~cm}^{-3}\right]$} & 1.7 & $10^{-3}$ \\
$D_{\mathrm{i}}$ & {$\left[\mathrm{cm}^{2} \mathrm{~s}^{-1}\right]$} & 3.2 & $10^{-8}$ \\
$\varepsilon$ & {$[-]$} & 0.40 & \\
$E_{\mathrm{z}}$ & {$\left[\mathrm{cm}^{2} \mathrm{~s}^{-1}\right]$} & 1.9 & $10^{-4}$ \\
$k_{\mathrm{l}}$ & {$\left[\mathrm{cm}^{3} \mathrm{~g}^{-1} \mathrm{~s}^{-1}\right]$} & \multicolumn{3}{c}{5.0} & \\
$k_{2}$ & {$\left[\mathrm{~s}^{-1}\right]$} & 9.5 & $10^{-5}$ \\
$k_{\mathrm{f}}$ & {$\left[\mathrm{cm} \mathrm{s}^{-1}\right]$} & 4.0 & $10^{-4}$ \\
$L$ & {$\left[\mathrm{~cm}^{-3}\right.$} & 10 & \\
$Q_{\mathrm{m}}$ & {$\left[\mathrm{g} \mathrm{cm}^{-3}\right]$} & 40 & $10^{-3}$ \\
$R$ & {$\left[\mathrm{~cm}^{-1}\right.$} & 5 & $10^{-3}$ \\
$u_{\mathrm{i}}$ & {$\left[\mathrm{cm} \mathrm{s}^{-1}\right]$} & 4.7 & $10^{-2}$ \\
$V_{\mathrm{L}}$ & {$\left[\mathrm{cm}^{3}\right]$} & 12.57 & \\
$V_{\mathrm{S}}$ & {$\left[\mathrm{cm}^{3}\right]$} & 18.85 & \\
\hline
\end{tabular}

The fit is obtained by using $k_{1}=12.75\left[\mathrm{~cm}^{3} \mathrm{~g}^{-1} \mathrm{~s}^{-1}\right]$ and $k_{2}=1.210^{-6}\left[\mathrm{~s}^{-1}\right], Q_{\mathrm{m}}=2.210^{-3}\left[\mathrm{~g} \mathrm{~cm}^{3}\right], C_{0}=1.5810^{-5}$ $\left[\mathrm{g} \mathrm{cm}^{3}\right], R=75.010^{-4} \mathrm{~cm}, V_{\mathrm{s}}=1.5 \mathrm{~cm}^{3}, V_{\mathrm{L}}=100 \mathrm{~cm}^{3}$, $D_{\mathrm{i}}=6.910^{-8} \mathrm{~cm}^{2} \mathrm{~s}^{-1}$ and is shown in Fig. 3. It shows the time variation of $\beta$-galactosidase concentration in bulk fluid phase of finite bath.

The availability of an exact solution provides a convenient check on the accuracy of the collocation solution. Rasmuson and Neretnieks [15] had given an analytical solution for a simplified fixed bed model. The analytical solution was obtained by assuming homogeneous diffusion in the particle phase and a linear equilibrium relation between free and adsorbed solute. The following dimensionless parameters are used: $\psi=6780, \theta=3, \xi=10000$, and $\mathrm{Pe}=1.93$. It is evident from Fig. 4 that the agreement is very good. The solutions show some divergence at low times. This is due to difference in the boundary conditions and not to any inaccuracy of the collocation solution. This is verified by repeating the collocation solution using the boundary conditions employed by Rasmuson and Neretnieks [15].

Fig. 5 shows a typical breakthrough curve for the adsorption step. Much of the information needed to evaluate col-

Table 4. Comparison of solute recovery efficiency.

\begin{tabular}{lll}
\hline Parameter & $\begin{array}{l}\text { Batch } \\
{[\%]}\end{array}$ & $\begin{array}{l}\text { Fixed bed } \\
{[\%]}\end{array}$ \\
\hline$C_{0} 10^{-3}$ & & \\
$1.710^{-3}$ & 95.4 & 96.7 \\
$k_{1}$ & 89.1 & 96.0 \\
1.0 & & \\
5.0 & 79.0 & 91.3 \\
$Q_{\mathrm{m}}$ & 89.1 & 96.0 \\
$8010^{-3}$ & & \\
$8010^{-3}$ & 89.1 & 96.0 \\
$R$ & 97.4 & 97.8 \\
$510^{-3}$ & & 96.0 \\
$110^{-2}$ & 89.1 & 89.0 \\
\hline
\end{tabular}

Table 5. Comparison of adsorbent utilization efficiency.

\begin{tabular}{lll}
\hline Parameter & $\begin{array}{l}\text { Batch } \\
{[\%]}\end{array}$ & $\begin{array}{l}\text { Fixed bed } \\
{[\%]}\end{array}$ \\
\hline$C_{0} 10^{-3}$ & & \\
$1.710^{-3}$ & 43.1 & 85.1 \\
$k_{1}$ & 78.0 & 87.0 \\
1.0 & & \\
5.0 & 73.6 & 78.1 \\
$Q_{\mathrm{m}}$ & 78.0 & 87.0 \\
$4010^{-3}$ & & \\
$8010^{-3}$ & 78.0 & 87.0 \\
$R$ & 31.6 & 87.5 \\
$510^{-3}$ & & \\
$110^{-2}$ & 78.0 & 87.0 \\
\hline
\end{tabular}


umn performance is contained in this curve. The shape of this curve is a result of a complex mix of equilibrium and nonequilibrium processes. After a while solute breakthrough occurs and the effluent concentration increases with time. At very long times the column becomes saturated, and the effluent concentration equals the feed concentration. The maximum capacity of the column for a given inlet concentration is equal to the area behind the breakthrough curve. The amount of solute that remains in the effluent is, of course, the area under the curve. The breakthrough curve will be a step function for favourable (equilibrium) separations, i.e., there will be an instantaneous jump in the effluent concentration from zero to the feed concentration at the moment the column capacity is reached. The spreading observed in actual breakthrough curves is due to the existence of flow non-idealities (channeling), mixing (axial dispersion and dead spaces) and finite mass transfer and sorption rates.

For quantitative comparison purpose, two efficiencies [7], i.e. solute recovery efficiency and bed utilization efficiency are defined in terms of area $S_{1}$ (= used column capacity), $S_{2}$ (= feed wasted), and $S_{3}$ (= unused column capacity) as shown in Fig. 5. Solute recovery efficiency is defined as

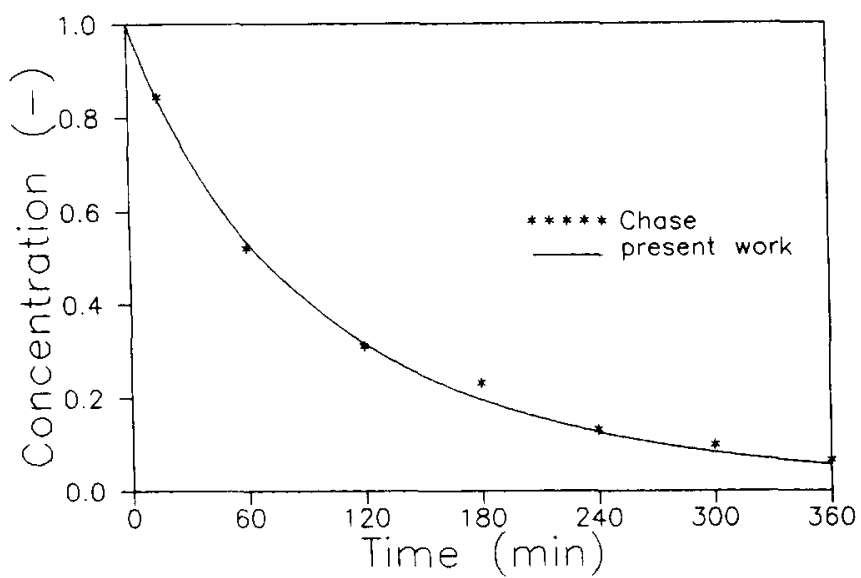

Figure 3. Verification of the batch model.

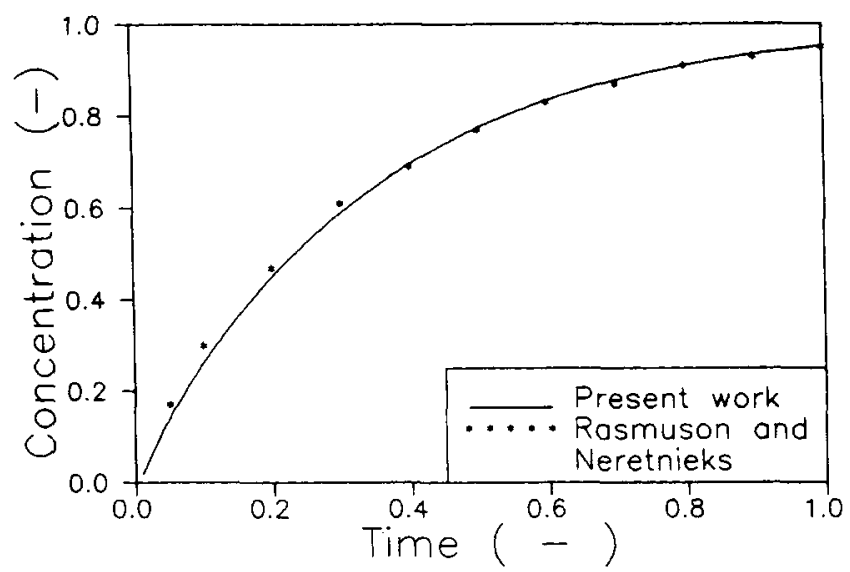

Figure 4. Comparison of numerical solution with exact analytical solution of Rasmuson and Neretnieks [15].
$S_{1} /\left(S_{1}+S_{2}\right)$ and adsorbent utilization efficiency as $S_{1} /\left(S_{1}+S_{3}\right)$. The determination of the breakthrough point and the shape of the curve affects the efficiencies of adsorption.

For the batch adsorption case, the corresponding efficiencies are defined as:

Solute recovery efficiency $=1-\frac{C}{C_{0}}$

Adsorbent utilization efficiency $=\frac{q}{Q_{\mathrm{m}}}$

Tab. 4 presents the solute recovery efficiencies for different parameters for the batch and fixed bed cases.

Tab. 5 presents the adsorbent utilization efficiencies for different parameters for the batch and fixed bed cases.

Fig. 6 displays the effect of solute concentration on both batch and fixed bed modes. As can be seen from Tabs. 4 and 5, a lean feed has better solute recovery efficiency and

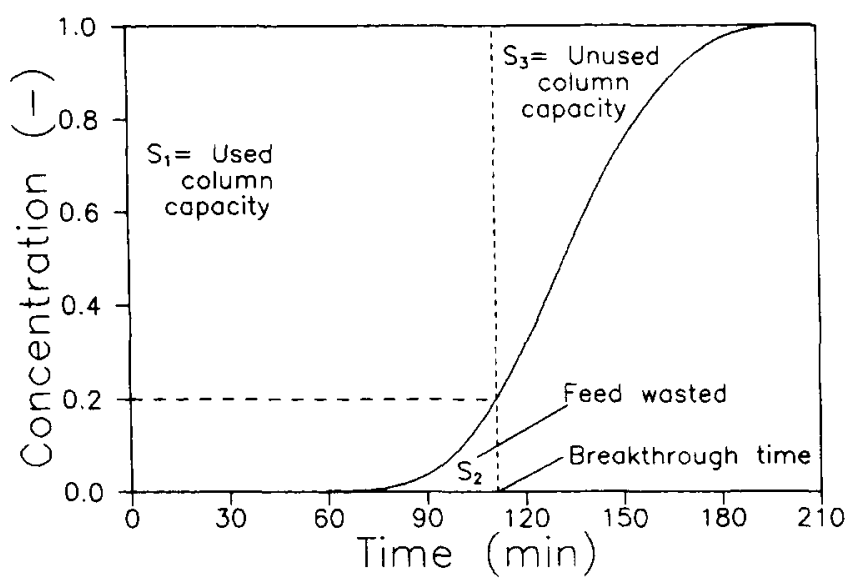

Figure 5. Breakthrough curve for affinity adsorption.

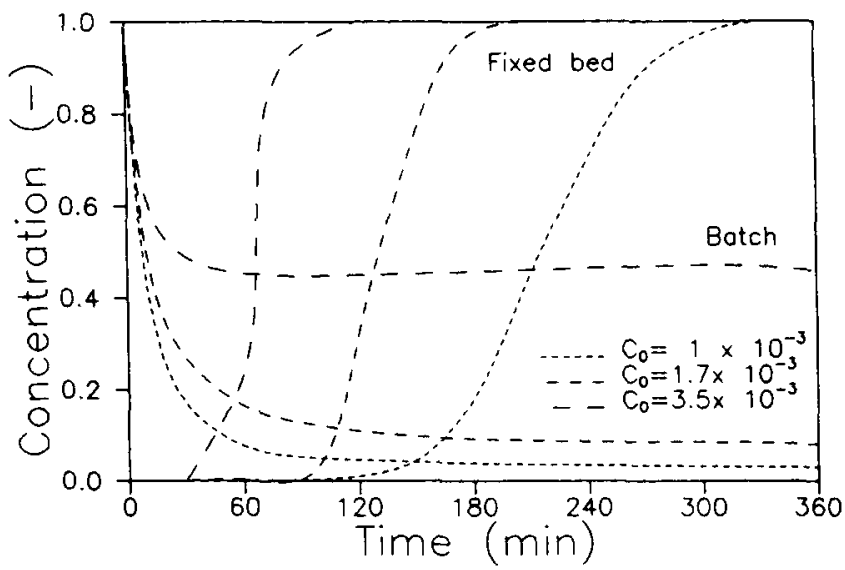

Figure 6. Effect of solute concentration. 
less adsorbent utilization efficiency. The change in inlet solute concentration markedly affects the shape and position of the breakthrough curve. The higher the solute concentration, the faster the breakthrough. Batch mode solute recovery efficiency compares well with that of fixed bed for a lean feed. However in the case of a fixed bed, the quantity of solution to be supplied is large when the solute concentration is low and an optimum value has to be arrived at. In such cases batch adsorption is recommended.

Fig. 7 evaluates the effect of reaction kinetics on the breakthrough behaviour of the solute. For both the cases, higher forward rate constant lead to better efficiencies with regard to both solute recovery and adsorbent utilization. The larger the forward rate constant, the sharper the breakthrough, thus improving adsorption efficiency. Faster rates of the forward rate constant allows local equilibrium conditions to be approached more quickly. Kinetic rate constants can be changed by changing the $\mathrm{pH}$ of the medium. Fixed bed more is efficient compared to that of batch mode.

Fig. 8 depicts the effect of ligand concentration on both batch and fixed bed modes. For the same inlet solute con-

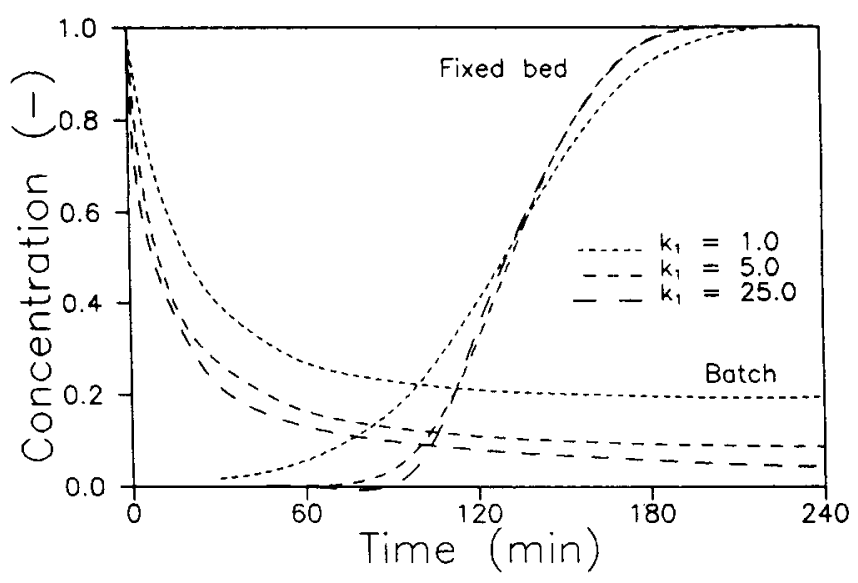

Figure 7. Effect of reaction kinetics.

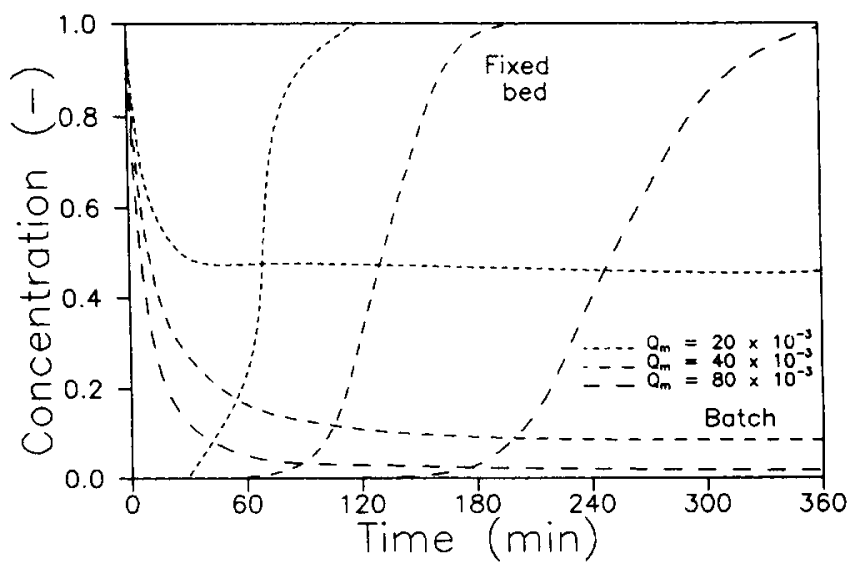

Figure 8. Effect of ligand concentration.

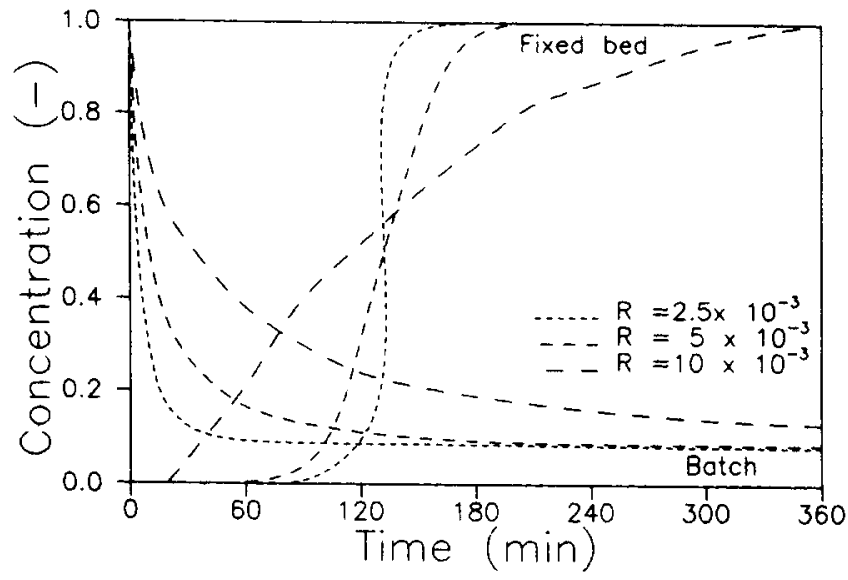

Figure 9. Effect of particle size.

centration, solute recovery efficiency and adsorbent utilization efficiency are evaluated for three different ligand concentrations. For the batch case, the higher the ligand concentration, the less the adsorbent utilization and better the solute recovery. Batch mode compares well with fixed bed in solute recovery for higher ligand concentrations. For fixed bed case, both the efficiencies increase with an increase in ligand content. When the adsorbent is costly, it is better to operate in fixed bed mode as this will lead to better adsorbent utilization.

Fig. 9 is the comparison of breakthrough curves for three particle sizes. Change in particle size affects the film mass transfer coefficient. Film mass transfer coefficient is inversely proportional to particle size for batch adsorption [16]. For example, if $u_{0}$ is unchanged, the Wilson and Geankoplis correlation [17] indicates that $k_{\mathrm{f}}$ is proportional to $R^{-2 / 3}$. Breakthrough is faster for larger particle sizes. Both the efficiencies decrease as particle size increase for both the cases. Batch mode is comparable to that of fixed bed mode in adsorbent utilization for larger particle size.

\section{Conclusions}

In the present study the following parameters have been shown to affect the solute recovery and adsorbent utilization efficiencies for batch and fixed bed modes: solute concentration, surface reaction kinetics, ligand loading, and particle size. The models account for film and pore diffusion mass transfer resistances, as well as the rate of interaction between solute and ligand. Axial dispersion is included in the packed bed model. By using the same governing mathematical equations, but by changing the initial and boundary conditions, washing and elution steps can be modeled. Design strategies are arrived at through solute recovery and adsorbent utilization efficiencies. Fixed bed adsorption is more efficient compared to that of batch adsorption. When the feed is lean, the batch mode will be preferable. 


\section{Acknowledgement}

The author would like to thank CSIR for the financial assistance (RA no. 9/79 (473)/94-EMR.I dated 14th July 1994).

Received: October 10, 1995 [CET 785]

\section{Symbols used}

C $\quad\left[\mathrm{g} \mathrm{cm}^{-3}\right]$

$C_{\mathrm{i}}\left[\mathrm{g} \mathrm{cm}^{-3}\right]$

$C_{0} \quad\left[\mathrm{~g} \mathrm{~cm}^{-3}\right]$

$D_{\mathrm{i}} \quad\left[\mathrm{cm}^{2} \mathrm{~s}^{-1}\right]$

$E_{2} \quad\left[\mathrm{~cm}^{2} \mathrm{~s}^{-1}\right]$

$k_{\mathrm{f}} \quad\left[\mathrm{cm} \mathrm{s}^{-1}\right]$

$K_{\mathrm{D}} \quad\left[\mathrm{g}^{-1} \mathrm{~cm}^{3}\right]$

$k_{1} \quad\left[\mathrm{~cm}^{3} \mathrm{~g}^{-1} \mathrm{~s}^{-1}\right.$

$k_{2} \quad\left[\mathrm{~s}^{-1}\right]$

L $[\mathrm{cm}]$

$\mathrm{Pe} \quad[-]$

$q_{\mathrm{i}} \quad\left[\mathrm{g} \mathrm{cm}^{-3}\right]$

$Q_{\mathrm{m}} \quad\left[\mathrm{g} \mathrm{cm}^{-3}\right]$

$r \quad[\mathrm{~cm}]$

$R \quad[\mathrm{~cm}]$

$t \quad[\mathrm{~s}]$

T $[-]$

$u_{\mathrm{i}} \quad\left[\mathrm{cm} \mathrm{s}^{-1}\right]$

$u_{0} \quad\left[\mathrm{~cm} \mathrm{~s}^{-1}\right]$

$V_{\mathrm{L}} \quad\left[\mathrm{cm}^{3}\right]$

$V_{\mathrm{s}} \quad\left[\mathrm{cm}^{3}\right]$

$Y_{1} \quad[-]$

$Y_{2} \quad[-]$ bulk fluid concentration of solute pore liquid concentration based on particle volume

feed concentration

effective particle diffusion coefficient

axial dispersion coefficient

film mass transfer coefficient

Langmuir constant

second order rate constant

first order rate constant

column length

Peclet number, $=L u_{0} / E_{\mathrm{z}}$

local adsorbed solute concentration based on particle volume

maximum adsorbed solute concentration based on particle volume

radial position in adsorbent particle

adsorbent particle radius

time

dimensionless time, $=t D_{\mathrm{i}} / R^{2}$

interstitial velocity

superficial velocity

volume of the liquid phase

total volume of the adsorbent particles

dimensionless local adsorbed solute concentra-

tion, $=q_{\mathrm{i}} / Q_{m}$

dimensionless pore liquid concentration, $=C_{\mathrm{i}} / C_{0}$

$$
\begin{array}{ll}
Y_{3} & {[-]} \\
Z & {[\mathrm{~cm}]} \\
z^{*} & {[-]} \\
\varepsilon & {[-]} \\
\nabla & {\left[\mathrm{cm}^{-1}\right]}
\end{array}
$$

dimensionless bulk fluid concentration of solute, $=C / C_{0}$ axial position in the percolation column

dimensionless axial coordinate, $=z / L$ column void fraction gradient

\section{References}

[1] Affinity Chromatography, Pharmacia Fine Chemicals, Uppsala 1979.

[2] Janson, J.C., Trends Biotechnol. 2 (1984) pp. 31-38.

[3] Scouten, W.H., Affinity Chromatography: Bioselective Adsorption on Inert Matrices, John Wiley and Sons, New York 1981.

[4] Lightfoot, E.N., Cockrem, M.C.M., Sep. Sci. Technol. 22 (1987) pp. 165.

[5] Arnold, F.H., Blanch, H.W., Wilke, C. R., Chem. Eng. J., Part B 30 (1985) No. 2, pp. 9-24.

[6] Firouztale, E., Scott, A.P., Dalvie, S.K., Von Blohn, G.M., AIChE Symp. Ser. 88 (1939) pp. 25-33.

[7] Yang, B.-L., Goto, M., Goto, S., Colloids Surfaces 37 (1989) pp. $369-378$.

[8] Sridhar, P., Sastri, N.V.S., Modak, J.M., Mukherjee, A.K., Chem. Eng. Technol. 17 (1994) pp. $422-429$.

[9] Foo, S. C., Rice, R.G., AIChE J. 21 (1975) pp. $1149-1158$.

[10] Danckwerts, P.V., Chem. Eng. Sci. 2 (1953) pp. $1-13$.

[11] Finlayson, B.A., Nonlinear analysis in chemical engineering, McGraw-Hill, New York 1980.

[12] Villadsen, J., Michelsen, M.L., Solution of differential equation models by polynomial approximation, Prentice-Hall, New Jersey 1978.

[13] Yamamoto, S., Nakanish, K., Matsuno, R., Kamikubo, T., Biotechnol. Bioeng. 25 (1983) pp. $1465-1483$.

[14] Chase, H.A., J. Chromatogr. 297 (1984) pp. 179-202.

[15] Rasmuson, A., Neretnieks, I., AIChE J. 21 (1980) pp. $1149-1158$.

[16] Geankoplis, C. J., Transport processes and unit operations, 2nd Ed., Allyn and Bacon, Boston 1983.

[17] Wilson, E.J., Geankoplis, C. J., Ind. Eng. Chem. Fund. 5 (1966) pp. $9-14$. 